\title{
The Acceptance of Smart Wearable Devices through Health Cognitive
}

\author{
Fen- Fen Huang ${ }^{1, a}$, Yi-Horng Lai ${ }^{1}$ \\ ${ }^{1}$ Department of Health Care Administration, Oriental Institute of Technology, New Taipei City, Taiwan
}

\begin{abstract}
Many people have become "health consumers" and "health conscious" by seeking products to more effectively manage health-related lifestyle aspects such as fitness activities, healthcare, sports, and rehabilitation. The results revealed that perceived ease of use, perceived usefulness, and health cognitive had a significant impact on attitude to use. To increase individuals' intention to use smart wearable devices, it is critical to encourage a positive attitude toward using the devices to acquire health knowledge. Emphasizing devising effective means to communicate the health utility of the devices to customers should be the highest priority for industry producers.
\end{abstract}

\section{General Instructions}

Remote health monitoring has the potential to improve the quality of health services and to reduce the total cost in healthcare by avoiding unnecessary hospitalizations and ensuring that those who need urgent care get it faster. Huge progress occurred in signal processing and mobile telecommunications as well as in humancomputer interface technologies and medical knowledge.

Remote health monitoring can significantly contribute to the enhancement of disease prevention, early diagnosis, disease management, treatment and home rehabilitation.

The healthcare and health delivery such as increase of, ageing population, chronic diseases though rehabilitation, monitoring, homecare and so on and by the remarkable progress in sciences and technologies. People become more "health conscious" and "health consumers" asking for better health and life style management, including healthcare, rehabilitation, fitness, sport, etc.

\section{Review of the Literature}

Variety of portable smart devices started to emerge in 21 st century. It allows people to use more advanced computing ability and offer instantaneous connectivity more than the personal computer [1]. In Addition, these smart devices provide a platform where people can easily access to the information that they need [2] and real-time information can be exchanged anywhere [3]. A smart wearable personal device should be light weight and low power consumption, of reasonable price by totally unskilled persons.

Health anxiety usually appears to be associated with increased worry [4], anxiety [5], and fear [6] though overall, during the experience of health anxiety. Most studies $[5,7]$ have examined cognitions and behaviors associated with health anxiety. Some health anxiety is

\footnotetext{
a Corresponding author: author@e-mail.org
}

associated with increased functional incidences of anxiety and depression [8]. Individuals with high health anxiety used more health care and caused higher costs for the health service [9].

Some studies on health anxiety have examined the cognitive processes in maintaining health anxiety [10]. A critical review of studies examining cognitive processes implicated in health anxiety [11] reported that health anxious individuals tend to negatively emotion as indicating an illness, a phenomenon known as amplification.

Behaviors associated with health anxiety are referred to as safety behaviors, which intention to protect one's health. The case with anxiety disorders, seeking behavior played a significant role in the maintenance of health anxiety [5, 12]. This study adopted Moon and Kim's (2001) definition of Perceived Playfulness in this study [13]. According to the authors, Perceived Playfulness can be defined as "the extent to which the individual perceives that the attention is focused on the interaction with the device; and finds the interaction intrinsically enjoyable or interesting."

Based on the theory of Flow [14], they considered playfulness as an intrinsic belief or motive, which is shared by the individual's experience with the environment. Flow represents most interesting experience possible when the person is unconsciously engaged in an activity such that he becomes so engrossed thereby losing the self-sense [15]. Flow experience can occur in structured activities such as sports, ritual events, games, artistic performances, and so on [14]. In other words, enjoyment, experiences of concentration, and curiosity in an activity characterize the experience of flow [16].

Other researchers have studied Perceived Playfulness in the mobile Internet services. In the study of mobile services, Nysveen et al. (2005) found playfulness plays a key role in determining user acceptance of these services 
[17]. Fang et al. (2006) founded mobile tasks that can be performed on handheld devices into some broad types [18]. It found Perceived Playfulness was significant when users perform gaming tasks. The results suggest Perceived Playfulness played a special role in user's favorable acceptance of mobile Internet services.

Technology Acceptance Model (TAM) has become the popular theory of technology use in the information systems literature [19]. Davis et al. (1989) developed the technology acceptance model (TAM) to specify the relationships, related attitude and behavior: perceived ease of use and perceived usefulness, and users' attitudes, behavioral intention and actual behavior [20]. There are two predictors of attitude to use a technology and highly predictive model. The first predictor is perceived usefulness. It refers to one's belief that using a technology will lead to desirable outcomes and usually involving an increase in personal effectiveness. The second predictor is perceived ease of use. It is one's belief that using the technology will be free of effort. Usability dimensions or other ease of use like time efficiency also be relevant in healthcare relative research [21].

\section{Method}

\subsection{Procedure}

The sample consisted of the people who attended road running in Taiwan. Roadrunners from six sections of the road running were invited to complete the questionnaire. A total of 163 questionnaires were returned. This study extended Davis's (1989) TAM to explore health anxiety and acceptance of mart wearable devices.

In this study, the model hypothesizes that road-runners perceived health anxiety and health cognitive had a significant influence on their perceived usefulness. The degree to which smart wearable device is easy to use, as perceived by roadrunners' experience, affects both their perception of the usefulness of the technology and their attitude toward using the technology in general.

Attitude is also influenced by the level of the technology's usefulness, as perceived by health anxiety and health cognitive. Finally, the intensity of roadrunners' intention to use a technology can be explained and predicted by their attitude toward using the technology and the technology's perceived usefulness.

SPSS 22 with the data also supported most of the individual causal paths postulated by TAM. We intend to provide an integrated theoretical basis to evaluate new generations of TAM and point out the potential problem of user acceptance. Behavior intention is predicted by both attitude and perceived usefulness. Perceived ease of use influences both attitude and perceived usefulness.

\section{Results}

As to the demand for smart wearable device, $82.8 \%$ (135) were willing to purchase the products at present. When asked about an acceptable payment for buying the smart wearable devices, $73.6 \%$ (120) of the respondents chose NTD $\$ 1,000$ or less. The result is consistent with previous studies.

There are significant relationships between health anxiety and the use frequency, devices' number of health information searching. People who are more anxious about their health are more likely to seeking health information frequently and using the smart wearable device. Health information could be used by people with an illness in order to understand their diagnosis and treatment options as well as by healthy people for risk evaluation and disease prevention.

In this study, most of the respondents are healthy persons. And the purpose of using the smart wearable device is to increase their health information. It is supposed that the smart wearable device is helpful for disease prevention and health promotion. The results revealed that perceived ease of use, perceived usefulness, and health anxiety had a significant impact on attitude to use.

Table 1. Description of participants

\begin{tabular}{lcc}
\hline Variables & $\mathrm{N}$ & $\%$ \\
\hline Gender & & \\
$\quad$ Male & 96 & $58 \%$ \\
$\quad$ Female & 67 & $41 \%$ \\
Education & & \\
$\quad$ University & 127 & $77 \%$ \\
$\quad$ High school & 36 & $22 \%$ \\
Marriage & & \\
$\quad$ Yes & 24 & $14 \%$ \\
$\quad$ No & 139 & $85 \%$ \\
Employment & & \\
Yes & 42 & $25 \%$ \\
$\quad$ No & 121 & $74 \%$ \\
Increasing health Information & & \\
$\quad$ Yes & 151 & $92 \%$ \\
No & 12 & $7 \%$ \\
\hline
\end{tabular}

Table 2. Regression Model

\begin{tabular}{llll}
\hline Variables & $\mathrm{B}$ & $\mathrm{t}$ & $\mathrm{p}$ \\
\hline Age & -0.009 & -1.691 & 0.051 \\
Marriage & -0.107 & -0.985 & 0.421 \\
Employment & 0.099 & 1.018 & 0.315 \\
Perceived usefulness & -0.271 & -3.239 & $0.003^{* *}$ \\
Perceived ease of use & 0.233 & 3.172 & $0.006^{* *}$ \\
Health anxiety & 0.36 & 4.121 & $0.000^{* *}$ \\
Increasing health information & 0.331 & 4.026 & $0.000^{* *}$ \\
Health cognitive & 0.182 & 2.916 & $0.010^{* *}$ \\
Constant & 0.216 & 3.013 & $0.009^{* *}$ \\
$\mathrm{R}$ & & 0.533 & \\
$\mathrm{R}$ square & & 0.284 & \\
\hline${ }^{*} \mathrm{p}<0.05, * * \mathrm{p}<0.01$ & & &
\end{tabular}

\section{Discussion and Conclusion}

This study represents research in examining the applicability of TAM to explaining roadrunners' acceptance of telecare technology. The model was evaluated using data collected from roadrunners 
practicing the smart wearable device in Taiwan. Some implications can be drawn from the findings of the study.

Lack of experience among the general public is one of the barrier to the development of the smart wearable device. This survey demonstrated that roadrunners agree with the concept and the potential benefits of the smart wearable device when they receive information. Another barrier is financial burden. Many roadrunners are not willing to pay for the smart wearable device unless it is inexpensive. The relative industry need to consider how to enhance public awareness of smart wearable devices' benefits and broadcast worthiness of purchasing the smart wearable device.

From a managerial standpoint, in order to raise individual intentions to use a technology, it is important to encourage a positive attitude about health anxiety toward using the technology. Positive perception of the technology's usefulness is crucial, whereas the technology's ease of use may not be equally important for professionals. Emphasize devising effective means to communicate the health cognitive of the technology to roadrunners should be the high priority task for the healthcare industry management.

\section{Competing Interests}

No conflicting interests can be indicated.

\section{Acknowledgements}

This research was supported by grants from the Far Eastern Memorial Hospital for the project of "exploring the hospital applications of smart wearable devices" (RD1040073).

\section{References}

1. Chen, J., Yen, D., \& Chen, K. The acceptance and diffusion of the innovative smartphone use. Information \& Management, 46, 241-248. (2009).

2. Lee, T. The impact of perceptions of interactivity on customer trust and transaction intentions in mobile commerce. Journal of Electronic Commerce Research, 6(3), 165-180. (2005).

3. Hennig-Thurau, T., Malthouse, E. C., Friege, C., Gensler, S., Lobschat, L., Rangaswamy, A., \& Skiera, B. The impact of new media on customer relationships, Journal of Service Research, 13(3), 311-330. (2010).

4. Longley P.A., M. F. Goodchild, D. J. Maguire and D. W. Rhind. Geographic Information Systems and Science. Second Edition. John Wiley, Chichester, (2005).

5. Abramowitz, J.S. \& Moore, E.L. An experimental analysis of hypochondriasis. Behavior Research and Therapy, 45, 413-424. (2007).

6. Fergus, T.A., Valentiner, D.P., McGrath, P.B., \& GierLonsway, S.L. Comparing Two Short-Form Versions of the Social Interaction Anxiety Scale and the Social Phobia Scale in a Clinical Sample. Paper presented at the 46th Annual ABCT Convention. (2012).

7. Gramling, A.A., J.W. Schatzberg, and W.A. Wallace. The role of undergraduate auditing coursework in reducing the expectations gap. Issues in Accounting Education 11 (1): 131-161. (1996).

8. Noyes, R., Happel, R. L., \& Yagla, S. J. Correlates of hypochondriasis in a nonclinical population. Psychosomatics, 40, 461-469. (1999).

9. Fink, P., Ørnbøl, E., \& Christensen, K.S. The outcome of health anxiety in primary care. A twoyear follow up study on health care costs and selfrated health. Plos One, 5, 1-12. (2010).

10. Lees A, Mogg K, Bradley BP. Healthy anxiety, anxiety sensitivity, and attentional biases for pictorial stimuli and linguistic health threat cues. Cognition Emotion; 19(3):453-62. (2005)

11. Williams M. J., McManus F., Muse K., \& Williams J. M. G. Mindfulness-based cognitive therapy for severe health anxiety (hypochondriasis): An interpretative phenomenological analysis of patients' experiences. British Journal of Clinical Psychology, 50, 379-397. (2011).

12. Olatunji, B. O., Etzel, E. N., Tomarken, A. J., Ciesielski, B. G., \& Deacon, B. J. The effects of safety behaviors on health anxiety: An experimental investigation. Behaviour Research and Therapy, 49, 719-728. (2011).

13. Moon, J. W., \& Kim, Y. G. Extending the TAM for a World-Wide-Web context. Information \& Management, 38(4), 217-230. (2001).

14. Csikszentmihalyi, M. The future of Flow. In M. Csikszentmihalyi \& I. S. Csikszentmihalyi (Eds.), Optimal experience: Psychological studies of Flow in consciousness (pp. 364-383). Cambridge University Press: New York. (1988).

15. Chung, J., \& Tan, F. B. Antecedents of Perceived Playfulness: An exploratory study on user acceptance of general information-searching Websites. Information \& Management, 41(7), 869-881. (2004).

16. Agarwal, R., \& Karahanna, E. Time flies when you're having fun: Cognitive absorbtion and beliefs about information technology usage. MIS Quarterly, 24(4), 665-694. (2000)

17. Nysveen, H., Pedersen, P. E., \& Thorbjørnsen, H. Intentions to use mobile services: Antecedents and cross-service comparisons. Journal of the Academy of Marketing Science, 33(3), 330-346. (2005).

18. Fang, X. W., Chan, S., Brzezinski, J., \& Xu, S. Moderating effects of task types on wireless technology acceptance. Journal of Management Information Systems, 22(3), 123-157. (2006).

19. Talukder, M., Harris, H., Mapunda, G. Adoption of innovations by individuals within organizations: An Australian study. Asia Pacific Management Review, 13(2), 463-480. (2008)

20. Davis, F.D., Bagozzi, R.P., Warshaw, P.R. User acceptance of computer technology: A comparison of two theoretical models. Management Science, 35(8), 982-1003. (1989) 
21. Gagnon, M.P., Godin, G., Gagne, C., Fortin, J.P., Lamothe, L., Reinharz, D., and Cloutier, A. An adaptation of the theory of interpersonal behaviour to the study of telecare adoption by heart disease patients. International Journal of Medical Informatics, 71, 103-115. (2003) 